\section{DCP OF THE MONTH: JULY 2016}

We are delighted to have chosen dental nurse

Naeema Nalban as BDJ Team's first DCP of the month.

I Naeema's entry to our competition, which

I was announced in the May issue of $B D J$

Team, was very impressive, so we would like to include it here:

I am a 25-year-old Oral Health Promoter I with a sincere passion for oral health. I

have been working within the Bradford

District Care Trust for the best part of three

years and provide a range of programmes

which vary from speaking to other health

I professionals, delivering workshops and

I attending schools. Our aim is to reduce oral

health inequalities in the Bradford District

based around the evidence interventions;

I I plan, design and coordinate health

I promotion interventions. I do this by creating

relevant resources that are underpinned

by the Public Health England document:

Delivering better oral health: an evidence-

I based toolkit for prevention.

Alongside my oral health role, I work as

a dental nurse in Bradford which is part of

the Unplanned Dental Care (UDC) service

for patients who require emergency dental

I treatment during out of hours. We mainly

I provide temporary treatments which in most

I cases are extractions, temporary fillings and

extirpation which need to be delivered in

a fast paced work ethic as there is a high

demand of patients waiting to be treated in a

I short time scale.

Alongside working within the dental

environment, I have been driven in

enhancing my knowledge within the field and

have undertaken courses which include:

- Preparing to Teach in the Lifelong Learning

Sector (PTLLS)

- Health Promotion/Public Health MSc Level

7 Certificate - Leeds Beckett University

- Dietitians Food Nutrition programme for

0-5 years - St Luke’s Hospital, Bradford

- Recently completed a Level 2 NCFE

certification for Awareness of Mental Health

Problems.

I have also offered my free time to nurse for the DentAid charity who offer their services

to treat patients who are not registered

(recently featured on Channel 4 news). This

I has been such a valuable experience seeing

I patients appreciate what is presented within

the clinic and providing robust treatment

to relieve them of their dental pain. It has

also been an honour to reach out to children

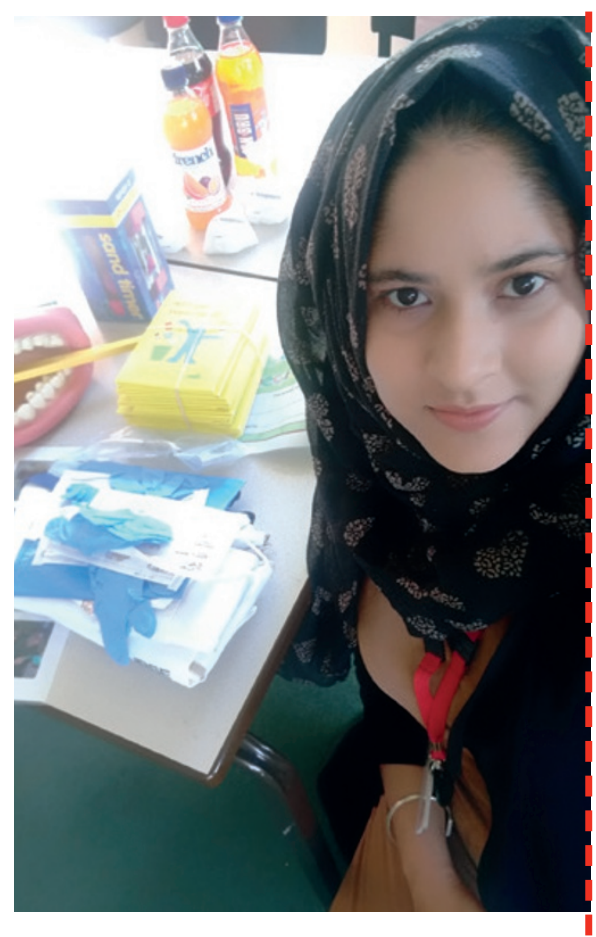

within my hometown of Dewsbury by attending a nursery to help them understand the concept of oral health and the importance of looking after their teeth.

I am very enthusiastic and passionate about sharing my knowledge and experience with a wide audience. I believe it is important to embed the concept of oral health from a young age, discussing key messages with the community, as it is such a colossal benefit in driving them to better health and well-being.

We would like to thank Naeema for entering our competition and wish her all the best with her endeavours, and with improving Bradford's oral health! Naeema wins a Little Bear demonstration puppet, sponsored by the Oral Health Foundation.

\section{DCP OF THE MONTH: SEPTEMBER: ENTRIES PLEASEI}

The next issue of BDJ Team is published on 2 September 2016. If you would like to be considered as DCP of the month for September, email the Editor, Kate Quinlan, k.quinlan@nature.com by 2 August 2016. All entries must include a photo.

The Little Bear and a range of other demonstration products, models and downloads can be purchased from the Oral Health Foundation shop at https://www. educatingsmiles.org/.

\section{BADT TO FOCUS ON AGE-APPROPRIATE HEALTHCARE}

According to the British Association of Dental Therapists (BADT), ageappropriate dentistry is essential to ensure successful dental health outcomes in an increasingly more expansive age range of dentate patients. The BADT will be focusing its annual conference on the Office for National Statistics figures that predict that more than one in 12 people in the UK will be aged over 80 by $2039 .{ }^{1}$

The BADT's 'Cradle to Grey' conference theme aims to increase awareness of the impact of age-related oral health care. Speakers will discuss periodontal disease and diabetes; medical challenges in dental patients; and prescribing rights. There will also be a discussion on career pathways to delivering age-related oral care in the twenty-first century and a presentation on the management of root caries. The presidential dinner will follow Friday's plenary sessions, with theory and hands-on practical skills sessions on Saturday.

The BADT Conference takes place at the DoubleTree by Hilton Piccadilly, Manchester on 23-24 September 2016 and offers 10.75 hours of verifiable CPD.

Early bird rates are available until 28 August and are:

- Members $£ 190$ (presidential dinner $£ 50$ )

- Newly qualified/student members $£ 150$

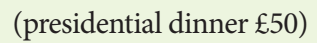

- Non-members $£ 220$ (presidential dinner $£ 60$ ).

To make a secure payment, visit www. badt.org.uk or call 01616655878 .

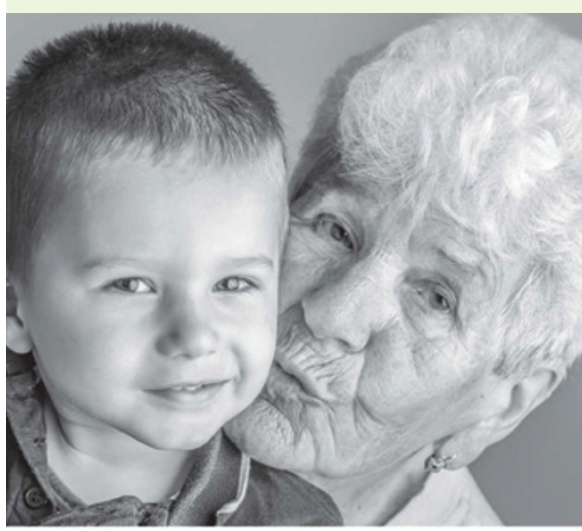

CRADLE TO GREY Age related oral care in the 21" century MANCHESTER $23^{*}-24^{n}$ September 2016 